\title{
Expression and correlation analysis of RegIV and vascular endothelial growth factors (VEGF-A and VEGF-C) in metastatic spinal tumors
}

\author{
SHUQUAN ZHANG ${ }^{1}$, GUANJIE ZHAO ${ }^{5}$, YI ZHAO ${ }^{3}$, RUI GU $^{4}$, \\ CHUANGANG PENG ${ }^{2}, \mathrm{ZHE} \mathrm{PU}^{1}$ and MINFEI WU ${ }^{2}$ \\ ${ }^{1}$ Department of Orthopedics, Tianjin Nankai Hospital, Tianjin 300100; ${ }^{2}$ Department of Orthopedics, \\ The Second Hospital of Jilin University, Changchun, Jilin 130041; ${ }^{3}$ Department of Surgery, \\ Peking Union Medical College Hospital, Beijing 100730; Departments of ${ }^{4}$ Orthopedics and ${ }^{5}$ Nephrology, \\ China-Japan Union Hospital, Jilin University, Changchun, Jilin 130033, P.R. China
}

Received June 27, 2016; Accepted December 13, 2016

DOI: $10.3892 / \mathrm{ol} .2017 .5871$

\begin{abstract}
The expression and correlation analysis of the regenerating gene family member 4 (RegIV) and vascular endothelial growth factors (VEGF-A and VEGF-C) in metastatic spinal tumors were studied. Fifteen patients with metastatic spinal tumors who underwent operation in our hospital from January 2011 to January 2013 were selected into this study. The expression level of tumor tissues in patients with spinal metastasis and RegIV, VEGF-A and VEGF-C of the corresponding paracancer normal tissue samples were evaluated by immunohistochemical staining method and the correlation between the expression of RegIV, VEGF-A and VEGF-C was analyzed. qRT-PCR results showed that the expression of RegIV was increased $(\mathrm{P}<0.05)$ in paracancer normal tissues and spinal metastatic tumor tissues. Compared with normal tissues, expression of RegIV, VEGF-A and VEGF-C was higher in metastatic spinal tumor tissues and the difference had statistical difference $(\mathrm{P}<0.05)$. Spearman's correlation analysis showed that the expression of RegIV was positively correlated with VEGF-A $(r=0.683, \mathrm{P}<0.05)$; the expression of RegIV positively correlated with VEGF-C $(\mathrm{r}=0.717, \mathrm{P}<0.05)$. Cox regression analysis showed that RegIV, VEGF-A, VEGF-C expression and microvessel density counts are prognostic factors affecting spine metastasis $(\mathrm{P}<0.05)$, RegIV expression affected the survival of patients with relative risk. The high expression of RegIV in spinal metastatic tumors may promote the expression of VEGF-A and VEGF-C
\end{abstract}

Correspondence to: Dr Minfei Wu, Department of Orthopedics, The Second Hospital of Jilin University, 218 Ziqiang Street, Changchun, Jilin 130041, P.R. China

E-mail: wumingfei1200@163.com

Key words: regenerating gene family member 4, metastatic spinal tumors, VEGF-A, VEGF-C, microvessel density to increase the microvascular density, promote angiogenesis, and accelerate the occurrence and progression of spinal metastatic tumors.

\section{Introduction}

Studies worldwide have reported that patients with medium or advanced cancer had a higher risk for bone metastasis, accounting for $50-85 \%$ (1). Bone metastasis in the spine is a relatively common site in clinic. The occurrence rate of spinal metastatic carcinoma is higher than that of primary malignant tumors. Previous findings showed that the growth and metastasis of tumor cells are inseparable from neovascularization, which is a necessary condition in the promotion of tumor growth in cells $(2,3)$. The principal factor that affects the generation of neovascularization is vascular endothelial cell growth factor (VEGF) (4). VEGF-A and VEGF-C are important members of the VEGF family and can promote endothelial cell migration and the construction of neovascularization.

The regenerating gene family member 4 (RegIV) is a new cancer gene. The expression of RegIV in carcinoma tissues, including gastric and colorectal cancers has been reported (5-8). Nevertheless, the studies on the expression of spinal metastatic carcinoma are not sufficient. Moreover, to the best of our knowledge, there is no study on the relationship of RegIV and the VEGF-A and VEGF-C correlation and microvessel density (MVD) of patients with spinal metastatic carcinoma. The current study aimed to reveal the expression of RegIV in spinal metastatic carcinoma and its correlation with angiogenesis in order to provide valuable reference for the studies on pathogenesis of spinal metastatic carcinoma.

\section{Patients and methods}

Patients and study criteria. Fifteen patients with spinal metastatic tumor who conformed to the conditions of this study and who were admitted to our hospital from January 2011 to January 2013 were selected and included in the study. 
Spinal metastatic tumor tissue was surgically removed and its corresponding normal tissue distant from lesion area was pathologically studied. Inclusion criteria were: i) All patients were diagnosed as spinal metastatic tumor; ii) without undergoing operation; iii) $>18$ years of age; iv) found with at least 1 symptom related to spine and spinal cord injury; and v) expected survival time was $>3$ months. Exclusion criteria were: i) Patients with primary spinal malignant tumor; ii) had been treated with spinal tumor operation; and iii) patients with poor physical condition, unable to adapt to the operational treatment implementation.

All the included cases in this study signed written informed consent. We obtained the approval of the Ethics Committee of Tianjin Nankai Hospital, all patients were planned to undergo operation.

\section{Methods}

Main reagents. The antibodies and reagents used were: i) Rabbit polyclonal RegIV antibody (dilution, 1:100; cat. no. sc-80320; Santa Cruz Biotechnology, Inc., Santa Cruz, CA, USA); ii) rabbit polyclonal anti-human VEGF-A antibody (dilution, 1:100; cat. no. dm-10343; Shanghai Duma Biological Technology Co., Ltd., Shanghai, China); iii) rabbit polyclonal anti-human VEGF-C antibody (dilution, 1:100; cat. no. dm-10456; Shanghai Duma Biological Technology Co., Ltd.); iv) DAB reagent and related immunohistochemical kit (Shanghai Jingke Chemical Technology Co., Ltd., Shanghai, China); and v) rabbit polyclonal anti-human FVIII antibody (dilution, 1:100; cat. no. BA0046; Wuhan Boster Biological Technology, Ltd., Wuhan, China).

Detection method. RegIV detection was carried out as follows. Streptomycin-biotin-peroxidase (SP) immunohistochemical method was used to measure the RegIV protein expression level, paraffin-embedded tissues were sectioned, and procedures were in strict accordance with the instructions. Known positive sections were regarded as the positive control, PBS instead of primary antibody as the negative control.

VEGF-A, VEGF-C, FVIII detection was identified using SP immunohistochemical method to measure VEGF-A, VEGF-C, FVIII expression on spinal metastatic tumor tissue and para-cancer normal tissue, and the FVIII-positive MVD was counted. Procedures of staining were in strict accordance with the instructions of the VEGF-A, VEGF-C, FVIII kits. Results of the staining were evaluated.

RegIV expression level was detected using RT-qPCR. Briefly, specimens were treated by liquid nitrogen, and total RNA was extracted by TRIzol reagent. A260/A280 values of total RNA detected by UV spectrophotometry were 1.8-2.0. RT-qPCR experiment was carried out according to the kit instructions. Reverse transcription system was $20 \mu 1$, RT was conducted in accordance with the following conditions: $37^{\circ} \mathrm{C}$ for $60 \mathrm{~min}$, and $95^{\circ} \mathrm{C}$ for $5 \mathrm{~min}$. The reaction system of PCR used $20 \mu \mathrm{l}$, and the reaction was carried out on the ABI7700 quantitative PCR in accordance with the following conditions: Initial activation of $95^{\circ} \mathrm{C}$ for $15 \mathrm{~min}$; 3-step cycle: at $94^{\circ} \mathrm{C}$ for $15 \mathrm{sec}$; at $55^{\circ} \mathrm{C}$ for $30 \mathrm{sec}$; at $70^{\circ} \mathrm{C}$ for $30 \mathrm{sec}, 30$ cycles in total. RNA U6 served as the internal reference, with reaction conditions are the same as above. The experiment was repeated 3 times, obtained data were analyzed by $R Q=2^{\Delta \Delta C q}$.
Observation index. RegIV expression level in spinal metastatic tumor tissue and paracancer normal tissue was observed, and the expression level of RegIV, VEGF-A, VEGF-C in spinal metastatic tumor tissue and paracancer normal tissue was contrasted. The effect of different pathological parameters on RegIV, VEGF-A, VEGA-C positive expression, as well as the correlation between RegIV and VEGF-A, VEGF-C expression were analyzed.

Evaluation criteria. i) We employed the semi-quantitative scoring method combined with Berry grading method (9): Positive expression of RegIV, VEGF-A, VEGF-C was stained with cytoplasm, scored, respectively, according to the positive cell rate and positive cell staining strength, expression level was determined by the staining degree: Staining score was the same with the negative control scored 0 point, pale yellow scored 1 point, pale brown scored 2 points, brown scored 3 points. It could be divided according to the proportion of positive cells in the observed cell: Number of positive cells 10\%: 1 point, $11-50 \%$ : 2 points, $51-75 \%$ : 3 points, $>75 \%$ : 4 points. Products of two scores: $0-3$ point was (-), $4-5$ points were $(+), 6-7$ points $(++),>8$ points $(+++), \leq 3$ points negative, $>3$ points positive.

ii) MVD count was based on Weidner and other methods (10): FVIII-labeled vascular endothelial cells with brownish yellow staining was positive standard, the lumen and vascular remodeling formation of positive endothelial cell clusters was regarded as a single microvessel number, and for the lumen area with diameter of $>8$ red cells, or vessels with a thicker layer, or single positive cell, the counts were not carried out. Three microvascular distribution areas with the highest density were selected, MVD count was carried out under high-power field of vision (x400), its average value was taken as the MVD value of this case.

Statistical analysis. SPSS 21.0 software (Chicago, IL, USA) was used for statistical analysis. Positive rates of various groups were tested by $\chi^{2}$, comparisons among groups were tested by t-test, correlation analysis was tested by Spearman's rank correlation. Relationship between the expression and prognosis of RegIV, VEGF-A, VEGF-C were measured by Cox regression analysis. $\mathrm{P}<0.05$ was considered statistically significant.

\section{Results}

RegIV expression level in spinal metastatic tumor tissue and paracancer normal tissue. RT-qPCR results showed that the expression level of RegIV in paracancer normal tissue and spinal metastatic tumor tissue increased successively, and differences were statistically significant $(\mathrm{P}<0.05)$ (Fig. 1).

Expression of RegIV, VEGF-A, VEGF-C in spinal metastatic tumor tissue and paracancer normal tissue. RegIV, VEGF-A, VEGF-C positive expression product presented brownish yellow particles (Figs. 2-4). RegIV expression positive rate of cancer tissue of patients with spinal metastatic tumor was $53.33 \%$, which was significantly higher than the RegIV expression positive rate of $6.67 \%$ of paracancer normal tissue $(\mathrm{P}<0.05)$ (Table I). VEGF-A expression positive rate of cancer 


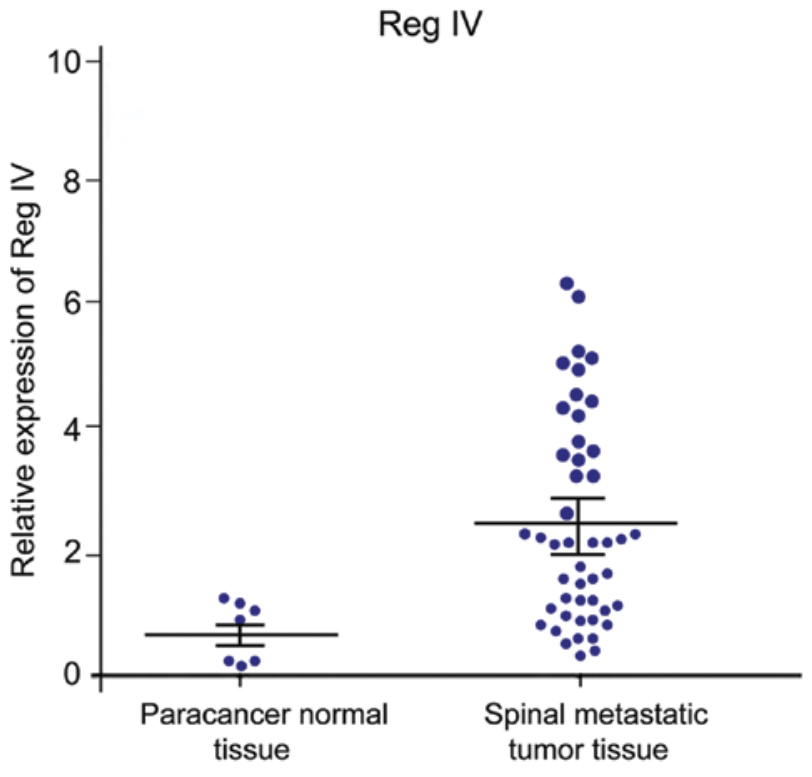

Figure 1. Relative expression level of RegIV in various tissues. RegIV, regenerating gene family member 4 .

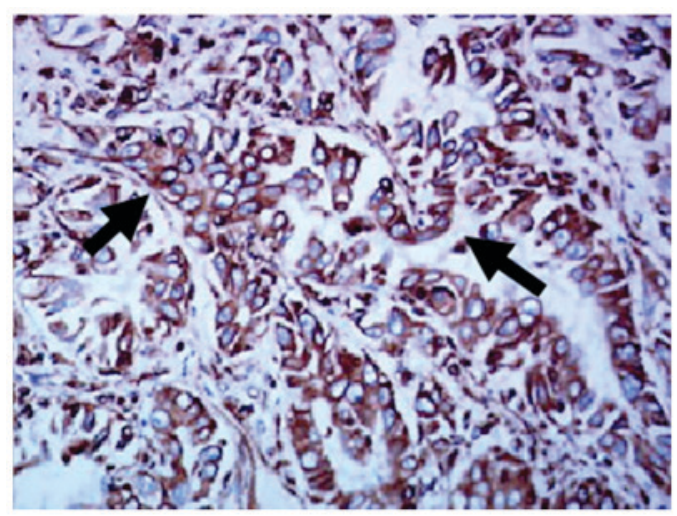

Figure 2. RegIV-positive expression in spinal metastatic tumor tissue (SP, x400). RegIV, regenerating gene family member 4; SP, streptomycin-biotin-peroxidase. Arrows show RegIV-positive staining.

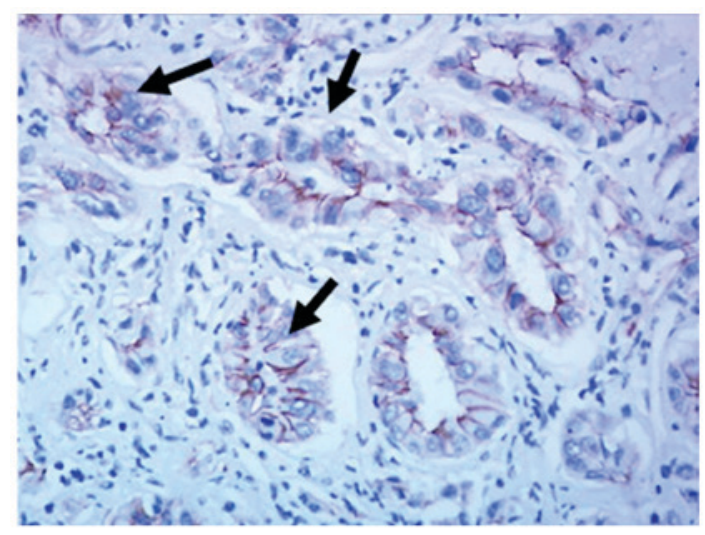

Figure 3. VEGF-A positive expression in spinal metastatic tumor tissue (SP, $x 400)$. VEGF, vascular endothelial growth factor; SP, streptomycin-biotin-peroxidase. Arrows show VEGF-A-positive staining.

tissue of patients with spinal metastatic tumor was $60 \%$, which was significantly higher than the VEGF-A expression positive

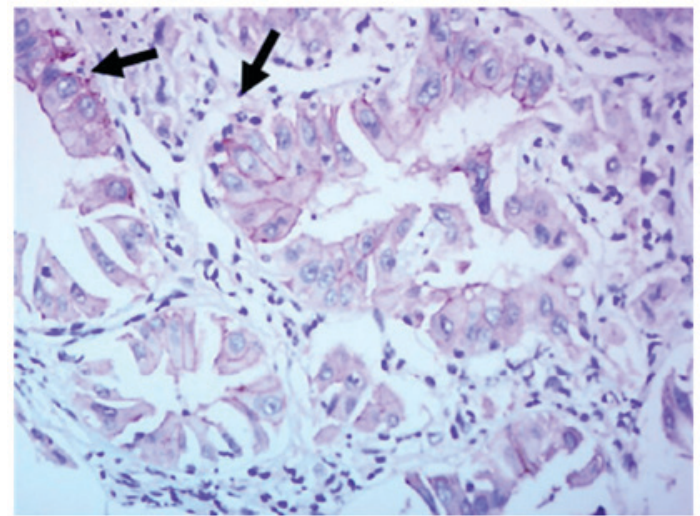

Figure 4. VEGF-C-positive expression in spinal metastatic tumor tissue (SP, x400). VEGF, vascular endothelial growth factor; SP, streptomycinbiotin-peroxidase. Arrows show VEGF-C-positive staining.

Table I. RegIV expression in spinal metastatic tumor and paracancer normal tissue (case).

\begin{tabular}{lcccccc}
\hline Group & $\mathrm{n}$ & + & ++ & +++ & $\begin{array}{r}\text { Positive } \\
\text { rate }(\%)\end{array}$ & - \\
\hline $\begin{array}{l}\text { Spinal metastatic } \\
\text { tumor tissue }\end{array}$ & 15 & 2 & 3 & 3 & 53.33 & 7 \\
$\begin{array}{l}\text { Paracancer } \\
\text { normal tissue }\end{array}$ & 15 & 1 & 0 & 0 & 6.67 & 14 \\
\begin{tabular}{l} 
P-value \\
\hline
\end{tabular} & & & & & & $<0.05$
\end{tabular}

RegIV, regenerating gene family member 4 .

Table II. VEGF-A expression in spinal metastatic tumor and paracancer normal tissue (case).

\begin{tabular}{lcccccc}
\hline Group & $\mathrm{n}$ & + & ++ & +++ & $\begin{array}{c}\text { Positive } \\
\text { rate }(\%)\end{array}$ & - \\
\hline $\begin{array}{l}\text { Spinal metastatic } \\
\text { tumor tissue }\end{array}$ & 15 & 3 & 3 & 3 & 60.0 & 6 \\
$\begin{array}{l}\text { Paracancer } \\
\text { normal tissue }\end{array}$ & 15 & 1 & 0 & 0 & 6.67 & 14 \\
\begin{tabular}{l} 
P-value \\
\hline
\end{tabular} & & & & & & $<0.05$ \\
\hline
\end{tabular}

VEGF-A, vascular endothelial factor A.

rate of $6.67 \%$ of paracancer tissue $(\mathrm{P}<0.05)$ (Table II). The VEGF-C expression positive rate of cancer tissue of patients with spinal metastatic tumor was $66.7 \%$, which was significantly higher than VEGF-A expression positive rate of $6.67 \%$ of paracancer tissue $(\mathrm{P}<0.05)$ (Table III).

Relationship between RegIV expression and VEGF-A, $V E G F-C$. The Spearman's correlation analysis revealed that, RegIV expression of spinal metastatic tumor tissue was positively correlated with VEGF-A expression $(r=0.683$, 
Table III. VEGF-C expression in spinal metastatic tumor and paracancer normal tissue (case).

\begin{tabular}{lcccccc}
\hline Group & & & \multicolumn{5}{c}{ Positive } \\
& $\mathrm{n}$ & + & ++ & +++ & rate $(\%)$ & - \\
\hline $\begin{array}{l}\text { Spinal metastatic } \\
\text { tumor tissue }\end{array}$ & 15 & 3 & 4 & 3 & 66.67 & 5 \\
$\begin{array}{l}\text { Paracancer } \\
\text { normal tissue }\end{array}$ & 15 & 1 & 0 & 0 & 6.67 & 14 \\
\begin{tabular}{l} 
P-value \\
\hline
\end{tabular} & & & & & & $<0.05$ \\
\hline
\end{tabular}

VEGF-C, vascular endothelial factor $\mathrm{C}$.

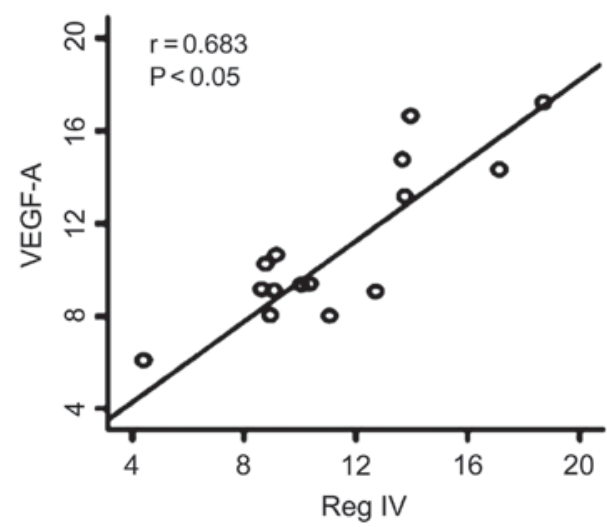

Figure 5. Analysis of correlation between RegIV and VEGF-A expression. RegIV, regenerating gene family member 4; VEGF, vascular endothelial growth factor.

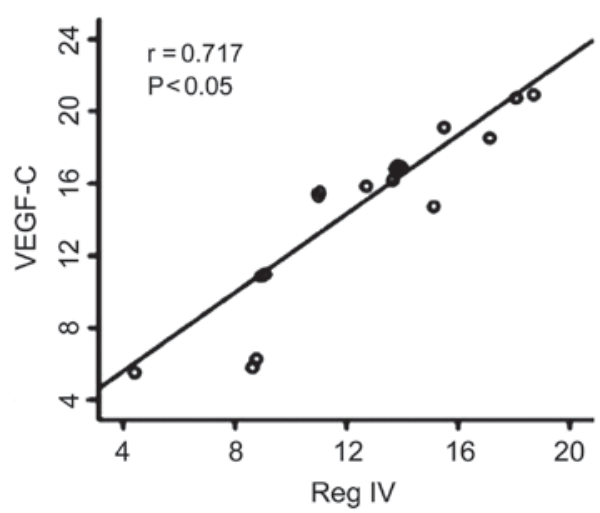

Figure 6. Analysis of correlation between RegIV and VEGF-C expression. RegIV, regenerating gene family member 4; VEGF, vascular endothelial growth factor.

$\mathrm{P}<0.05$ ) (Fig. 5). RegIV expression of spinal metastatic tumor tissue was positively correlated with VEGF-C expression $(\mathrm{r}=0.71, \mathrm{P}<0.05)$ (Fig. 6).

MVD comparison of tumor tissue of RegIV-positive expression cases and paracancer normal tissue. MVD value of RegIV expression cases of spinal metastatic tumor tissues was $57.67 \pm 4.43$, which was significantly higher than that of paracancer normal tissue $(40.53 \pm 2.71)(\mathrm{P}<0.05)$ (Fig. 7).

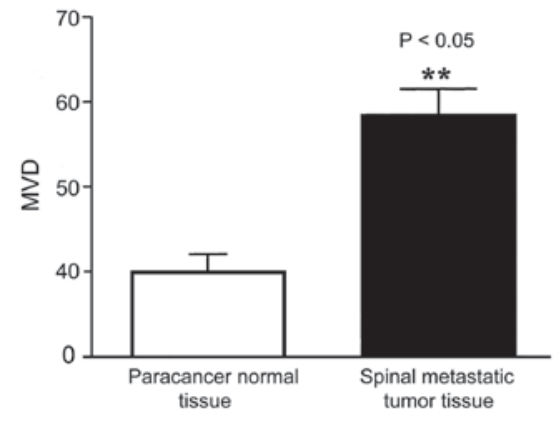

Figure 7. MVD comparison of tumor tissue of RegIV positive expression cases and paracancer normal tissue. MVD, microvessel density; RegIV, regenerating gene family member $4 .{ }^{* *} \mathrm{P}<0.05$ vs control.

Table IV. Cox regression analysis of RegIV, VEGF-A, VEGF-C expression and MVD count.

\begin{tabular}{lccccc}
\hline Index & $\mathrm{U}$ & $\mathrm{s}$ & Wald & P-value & RR \\
\hline RegIV & 0.67 & 0.28 & 5.89 & 0.02 & 1.93 \\
VEGF-A & 0.21 & 0.17 & 1.66 & 0.03 & 1.33 \\
VEGF-C & 0.55 & 0.26 & 4.72 & 0.04 & 1.74 \\
MVD & 0.43 & 0.22 & 3.15 & 0.02 & 1.54 \\
\hline
\end{tabular}

RegIV, regenerating gene family member 4; VEGF-A, vascular endothelial growth factor A; VEGF-C, vascular endothelial growth factor C; MVD, microvessel density; RR, relative risk.

Follow-up result. The average follow-up time was 18.4 months (4.5-36 months), there was no lost follow-up. Survival rate 1 year after operation was $65.42 \%, 2$ years was $19.35 \%$, and 3 years was $7.26 \%$.

Cox regression analysis. RegIV, VEGF-A, VEGF-C positive expression value and MVD count were analyzed by Cox proportional hazard model. Results showed that, RegIV, VEGF-A, VEGF-C expression and MVD count were the factors that affected prognosis of spinal metastatic tumors $(\mathrm{P}<0.05)$, RegIV positive expression had the maximum relative risk (RR) to the patient survival (RR) (Table IV).

\section{Discussion}

In the skeletal system of human body, spine is the tumor location easily transferred to and invaded. Autopsy for cancer patients found that over $90 \%$ of patients had spinal metastasis (11). Studies showed that the growth and metastasis of tumor cells were closely related to the generation of neovascularization (11-13). VEGF-A and VEGF-C adjusted angiogenesis mainly through the following two ways (14-16): i) Increasing the permeability of microvessel; ii) promoting the growth, proliferation and migration of endothelial cells through acting on the specific receptors on endothelial cells; the upregulated expression of VEGF-A and VEGF-C was closely related to hypoxia. Previous findings showed that inhibiting the expression of VEGF-A and VEGF-C of tumor tissues successfully inhibited the metastatic phenotypes of 
various tumors, including breast, gastric cancer and colon cancers, and even reversed the malignant phenotype of tumors (17).

Regenerating gene (Reg) family is a micromolecular and multifunctional secreted protein. These family members are similar in gene structure and can be divided into four subtypes (I, II, III and IV). Their functional characteristics are equivalent to that of acute phase protein and defenders against apoptotic death, and they all positively take part in the occurrence and development process of tissue injuries, tumor and inflammation. A previous study (18) showed that Reg family mainly had a low expression level in gastrointestinal tract, but in situ or atopic high expression was evident in case of tissue injuries. However, RegIV, as the newest member of Reg family, was first separated and obtained from patients with inflammatory bowel disease and it was hoped to become a biomarker to mark highly malignant potential (19). At present, the correlation between the expression of RegIV in patients with spinal metastatic carcinoma and angiogenesis remains unknown.

In this study, the positive expression rates of RegIV, VEGF-A and VEGF-C in spinal metastatic carcinoma tissues were 53.33, 60 and $66.67 \%$, respectively, which were significantly higher than the positive expression rate in paracancer normal tissue $(\mathrm{P}<0.05)$. This indicated that RegIV, VEGF-A and VEGF-C may play an important role in the occurrence and development of spinal metastatic carcinoma.

According to relevant analysis of Spearman, the expression of RegIV in spinal metastatic carcinoma tissues was positively correlated with the expression of VEGF-A $(\mathrm{r}=0.683, \mathrm{P}<0.05)$, the expression of RegIV in spinal metastatic carcinoma tissues was positively correlated with the expression of VEGF-C $(r=0.717, \mathrm{P}<0.05)$. The MVD value of RegIV expression cases in spinal metastatic carcinoma tissues was $57.67 \pm 4.43$, which was significantly higher than the MVD value in paracancer normal tissue $(40.53 \pm 2.71)$ $(\mathrm{P}<0.05)$. This result suggested that RegIV was an important positive regulator for angiogenesis and could promote the generation of neovascularization in spinal metastatic carcinoma tissues by activating the expression of VEGF-A and VEGF-C as well as upregulated VEGF-A and VEGF-C. Its mechanism may be that RegIV could carry out repeated degradation for vascular basement membrane and extracellular matrix, promote the migration of vascular endothelial cells and trigger the formation of neovascularization; while VEGF-A and VEGF-C changed the active form of endothelial cells and promoted tumor cells to pass through matrix, thus to induce the occurrence of tumor infiltration and metastasis.

In conclusion, high expression of RegIV in spinal metastatic carcinoma may increase microvessel density and promote angiogenesis by promoting the expression of VEGF-A and VEGF-C, thereby accelerating the occurrence and progression of spinal metastatic carcinoma. Therefore, in clinical treatment for patients with spinal metastatic carcinoma, the method of targeted therapy can be taken into consideration to inhibit the expression of RegIV, VEGF-A and VEGF-C so as to block tumor activity, adjusting the pathway of tumor angiogenesis, markedly reducing malignant degree of tumor and improving prognosis of patients.

\section{References}

1. Van Cutsem E, Köhne CH, Hitre E, Zaluski J, Chang Chien CR, Makhson A, D'Haens G, Pintér T, Lim R, Bodoky G, et al: Cetuximab and chemotherapy as initial treatment for metastatic colorectal cancer. N Engl J Med 360: 1408-1417, 2009.

2. Strube A, Hoffmann J, Stepina E, Hauff P, Klar U and Käkönen SM: Sagopilone inhibits breast cancer bone metastasis and bone destruction due to simultaneous inhibition of both tumor growth and bone resorption. Clin Cancer Res 15: 3751-3759, 2009.

3. Murakami H, Kawahara N, Demura S, Kato S, Yoshioka K and Tomita K: Total en bloc spondylectomy for lung cancer metastasis to the spine. J Neurosurg Spine 13: 414-417, 2010.

4. Eastley N, Newey M and Ashford RU: Skeletal metastases - the role of the orthopaedic and spinal surgeon. Surg Oncol 21: 216-222, 2012.

5. Patchell RA, Tibbs PA, Regine WF, Payne R, Saris S, Kryscio RJ, Mohiuddin M and Young B: Direct decompressive surgical resection in the treatment of spinal cord compression caused by metastatic cancer: a randomised trial. Lancet 366 : 643-648, 2005.

6. Inoue T, Oh RJ and Shiomi H: New approach for treatment of vertebral metastases using intensity-modulated radiotherapy. Strahlenther Onkol 187: 108-113, 2011.

7. Arrigo RT, Kalanithi P, Cheng I, Alamin T, Carragee EJ, Mindea SA, Park J and Boakye M: Predictors of survival after surgical treatment of spinal metastasis. Neurosurgery 68: 674-681, discussion 681, 2011.

8. Cole JS and Patchell RA: Metastatic epidural spinal cord compression. Lancet Neurol 7: 459-466, 2008.

9. Stieler F, Wolff D, Bauer L, Wertz HJ, Wenz F and Lohr F: Reirradiation of spinal column metastases: comparison of several treatment techniques and dosimetric validation for the use of VMAT. Strahlenther Onkol 187: 406-415, 2011.

10. Tokuhashi Y, Matsuzaki H, Oda H, Oshima M and Ryu J: A revised scoring system for preoperative evaluation of metastatic spine tumor prognosis. Spine 30: 2186-2191, 2005.

11. Lee BH, Kim TH, Chong HS, Moon ES, Park JO, Kim HS, Kim SH, Lee HM, Cho YJ, Kim KN, et al: Prognostic factor analysis in patients with metastatic spine disease depending on surgery and conservative treatment: review of 577 cases. Ann Surg Oncol 20: 40-46, 2013.

12. Tabouret E, Cauvin C, Fuentes S, Esterni B, Adetchessi T, Salem N, Madroszyk A, Gonçalves A, Casalonga F and Gravis G: Reassessment of scoring systems and prognostic factors for metastatic spinal cord compression. Spine J 15: 944-950, 2015

13. Zhang D, Xu W, Liu T, Yin H, Yang X, Wu Z and Xiao J: Surgery and prognostic factors of patients with epidural spinal cord compression caused by hepatocellular carcinoma metastases: retrospective study of 36 patients in a single center. Spine (Phila Pa 1976) 38: E1090-E1095, 2013.

14. Santini D, Tampellini M, Vincenzi B, Ibrahim T, Ortega C, Virzi V, Silvestris N, Berardi R, Masini C, Calipari N, et al: Natural history of bone metastasis in colorectal cancer: final results of a large Italian bone metastases study. Ann Oncol 23: 2072-2077, 2012.

15. Scagliotti GV, Hirsh V, Siena S, Henry DH, Woll PJ, Manegold C, Solal-Celigny P, Rodriguez G, Krzakowski M, Mehta ND, et al: Overall survival improvement in patients with lung cancer and bone metastases treated with denosumab versus zoledronic acid: Subgroup analysis from a randomized phase 3 study. J Thorac Oncol 7: 1823-1829, 2012.

16. Escudier B, Szczylik C, Porta C and Gore M: Treatment selection in metastatic renal cell carcinoma: expert consensus. Nat Rev Clin Oncol 9: 327-337, 2012.

17. Shostak K and Chariot A: EGFR and NF- $\kappa B$ : partners in cancer. Trends Mol Med 21: 385-393, 2015.

18. Crnalic S, Hildingsson C, Wikström P, Bergh A, Löfvenberg R and Widmark A: Outcome after surgery for metastatic spinal cord compression in 54 patients with prostate cancer. Acta Orthop 83: 80-86, 2012.

19. Tatsui CE, Suki D, Rao G, Kim SS, Salaskar A, Hatiboglu MA, Gokaslan ZL, McCutcheon IE and Rhines LD: Factors affecting survival in 267 consecutive patients undergoing surgery for spinal metastasis from renal cell carcinoma. J Neurosurg Spine 20: 108-116, 2014 